pendent of $\mu_{\mathrm{r}}$ in the other, are to be understiood in reference to a particular shape. 'The early treatments of magnetism were based on the formulae for isolated poles, so when the same formulae aro applied to magnets the shape assumed is that for which the magnet approximates to an ideal dipole, namely bar-shaped. The formulae must then only be used within their range of applicability. (For a magnet which is infinitesimally thin, the field at all points at a finite distance is indistinguishable from the field of a pair of isolated poles.) Kennelly is in this respect an MKS version of the traditional theory of electromagnetism, and his views presuppose the bar shape; Sommerfeld is explicit on the question of shape ${ }^{1}$. Thus it is incorrect to apply the relations uncritically to an ellipsoidal shape.

Both the traditional and the Sommerfeld systems are self-consistent, in magnetic media as well as vacuum. The two theories, however, make different statements about observable results; therefore they are not both consistent with the facts. The difference between them is of fact, not of arbitrary convention. The difference is not shown simply in the position of $\mu_{r}$, for this difference can be accommodated by a different interpretation of magnetic moment. The difference in factual content comes when one asserts what magnetic quantities are constant. I gave the references previously ${ }^{2}$.

An experiment has been performed ${ }^{3}$, which decided in favour of the traditional view, and against the view now associated with the name of Sommerfeld; but it was not satisfactory and should be repeated. But in the meanwhile one can readily show that the factual falsity of Sommerfeld follows from the basic equations of magnetostatics, namely, $\operatorname{div} \mathbf{B}=0$, curl $\mathbf{H}=0, \mathbf{B}=(\mathbf{H}+\mathbf{M}) / \mu_{0}$, if one supposes that an idcal "hard" magnet is one in which magnetization $\mathbf{M}$ is unchanging. I propose publishing a fuller discussion on another occasion.
The clear understanding of electromagnetism is difficult; it is therefore important to eliminate mistakes as quickly as possible.

Yours faithfully, H. V. STOPES-RoE

Department of Extra-mural Studies,

University of Birmingham. ${ }^{1}$ Sommerfeld, A., Lectures on Theoretical Physics: III, Electrodynamics,
41, 87 (Academic Press, New York, 1952).

${ }^{2}$ Stopes-Roe, H. V., Nature, 224, 579 (1969).

${ }^{3}$ Sargant, E. B., Phil. Mag., 14, 395 (1882).

\section{Disputed Pronoun}

SIR,- It is simple to makc the disputed sentence make sense by re-arranging the clauses in their syntactical order of importance-a sequence used by every competent journalist in this country. Thus: "John was surprised to learn (that) he had won the race." Mis-related participles are unacceptable because of their lack of precision.

I must confess surprise that the medical and scientific communities, who put so much stress on publication, are unaware of this basic rule, which is, I admit, related in practice to the degree of concentration available for sentence construction.

What does genuinely worry me is that people who can not set down their thoughts clearly may not be capable of thus assembling them. I trust, to preserve our belief in the omniscience of the communities concerned, I am forthwith proved wrong.

Yours faithfully, Aristair Campsie

Highfield East,

Bridge of Allan,

Scotland.

\title{
Obituary
}

\section{Professor W. O. Kermack}

Wruliam OGILvy Kermack, who died on July 20, 1970, made distinguished contributions to chemistry, biochemistry and statistics. Ho was born in Kirriemuir, Angus, on April 26, 1898, attended Webster's Seminary, Kirriemuir, and graduated at the University of Aberdeen in 1918. The following year he joined Professor W. H. Perkin, jun., at the Dyson Perrins Laboratory, Oxford, and succeeded in synthesizing heterocyclic compounds related to the alkaloid harmaline. In 1921 he became head of the chemical research laboratory, Royal College of Physicians, Edinburgh, but a laboratory accident in June 1924 rendered him totally blind. Such a catastrophe, which would have ended most research careers, presented a challenge to him to seek a way of resuming his scientific life. This he was able to achieve by the careful design of experiments which were undertaken by others under his direction. He kept abreast of the literature by having selected articles read to him, sometimes by colleagues, but especially by his wife without whose help he could not have continued. By 1930, in addition to his work in synthetic organic chemistry, he had studied the mechanism of flocculation of colloidal solutions and investigated certain aspects of glyconeogenesis.

After 1930 , his organic chemical interests led him to look for new antimalarials. Many new quinoline and acridine derivatives were synthesized and, later, some substituted pyridoacridines and phenanthrolines, a few of which had great chemotherapeutic potency. The decade $1930-1940$ was also the period of his greatest activity in the sphere of medical statistics, where he made important contributions to the mathematical theory of epidemics. At the same time, he began to write review articles on recent advances in biochemistry. Over a period of twenty years, few aspects escaped his notice. In 1938, he collaborated with Dr Philip Eggleton in writing The Stuff We're Made Of. This layman's guide to the basic sciences on which biochemistry is founded is still an entertaining book.

In 1949 he was appointed to the Macleod Smith chair of biological chemistry in the University of Aberdeen and characteristically accepted the task of creating a new department. His teaching commitments, University administrative duties, committee work in connexion with local research institutes, and plans for a School of Biochemistry left little time for research, yet he managed to study several biochemical problems principally concerned with amino-acids and enzymology. By the time of his retirement in 1968, he had established an active and effective department of high reputation.

During his career, many honours came his way, including Fellowship of the Royal Society of Edinburgh (1924), honorary LID of St Andrews University (1937) and Fellowship of the Royal Society (1944). His scientific knowledge was broadly based and the clarity of his thinking, the logic of his arguments and his understanding of first principles were widely acknowledged. His advice was always generously given to colleagues who brought their problems to him. He enjoyed discussion within a small group, and had a good memory for scientific anec. dotes and a sense of fun. His achievements would have been remarkable for anyone, but for a man blinded so early in life they could well be unique. 